\title{
LIFESTYLE MOBILITIES: A POLITICS OF LIFESTYLE ROCK CLIMBING
}

Jillian M. Rickly, PhD

The University of Nottingham

Nottingham University Business School

Wollaton Road

Nottingham, NG8 1BB, United Kingdom

Office Phone: (+44) 01158466493

jrickly@gmail.com

\begin{abstract}
The conceptualization of 'lifestyle mobilities' has yet to fully account for the diversity within and across mobile communities in terms of leisure, travel, and identity. Lifestyle rock climbers, for example, maintain minimalist, hypermobile lifestyles in the full-time, nonprofessional pursuit of the sport. In an effort to interrogate lifestyle rock climbing within the broader conceptualization of lifestyle mobilities, this paper applies Cresswell's (2010) mesotheoretical 'politics of mobility' framework. It begins by tracing constellations of mobility and historical contexts within the rock climbing community more broadly. This is followed by an examination of the facets of a politics of mobility: motive force, speed, rhythm, route, experience, friction, turbulence and remove, which together offer more nuanced understandings of the movement patterns and travel decisions of lifestyle climbing. However, to account for the community dynamics of lifestyle mobilities, there is a need to delve deeper and attend to the social relations that result from collective performances.
\end{abstract}

Keywords: Lifestyle mobilities, rock climbing, politics, leisure, sport 


\section{Introduction}

The last decade or so has brought about a refocusing on the ways that the social sciences think about movement and mobility. This 'new' mobilities paradigm (Sheller and Urry, 2006) might be shedding fresh light on the spatiality and connectedness of our world by considering multiple scales of movement, from the microbial to the bodily to global trade and information flows; yet, the ways in which these spheres intersect, alter and coalesce are not necessarily new. Indeed, Cresswell (2010, p.18) suggests, 'movements of one kind or another have been at the heart of all kinds of social science (and particularly geography) since their inception'. Nevertheless, this proliferation of interdisciplinary scholarship oriented around 'mobilities' hints at a revived interest in considering the movements (and moorings) of humans, information and non-human things from different and multidisciplinary perspectives. In fact, Cresswell's (2010) recent article on the politics of mobility is inspiring a flurry of scholarship (notably Vannini, 2011; Crang \& Zhang, 2012; Cresswell \& Martin, 2012; Kabachnik, 2012; Vannini \& Taggart, 2012), including this paper, which expands the interrogation of the politics of mobility to the concept of lifestyle mobilities.

A politics of mobility is a mesotheoretical approach that identifies six constituent parts of mobility: motive force, velocity, rhythm, route, experience and friction (Cresswell, 2010). Such an approach encourages a finer scale of analysis and, therefore, a more nuanced understanding of what drives and hinders the movement of one's mobile subject. In addition to these facets of mobility, this study incorporates 'turbulence' (Cresswell \& Martin, 2012) and 'remove' (Vannini, 2011), which are particularly salient to the form of lifestyle mobility of interest here. By focusing on lifestyle rock climbing, this paper investigates a particular iteration of lifestyle sport mobility in which rock climbers give up more sedentary residences to pursue the sport full-time. In so doing, they find employment (temporary or Internet-based) along the way so as to support their hypermobile lifestyles, as 
these climbers are, importantly, non-professionals. This is a global trend, with international travel circuits; however, observations of online forums suggest lifestyle rock climbers are overwhelming of North American origin and travel predominantly to sites in the United States. And while rock climbing is the primary factor informing their travel behavior and lifestyle choice, that fact does not fully answer the question: What is lifestyle rock climbing? Further, while lifestyle rock climbing is the focus of this study, there are number of similarities to other action sport mobilities in terms of motivations and experiences (see Boon, 2006; Duncan, 2008; Thorpe, 2012, 2014; Wheaton, 2004). From her research in this field, Thorpe $(2012,2014)$ in particular advocates the need for greater consideration of both the macro- and micro-mobilities of lifestyle sports. Accordingly, Cresswell's (2010) mesotheoretical framework is a useful approach, as a politics of mobility attends to the power relations of major socio-economic structures but also the everyday and sometimessubtle politics that influence movement and produce particular social relations.

This paper begins with a brief review of a more recent concept in mobilities studies lifestyle mobilities - and proceeds to a discussion of the research design that framed this project with lifestyle rock climbers. Following this, an analysis of lifestyle climbing takes account of the 'constellations of mobility' (Cresswell, 2010) that illustrate its historical, subcultural and geographic contexts. Next, a politics of lifestyle climbing is presented by moving through each of the facets of mobility so as to demonstrate the ways these constituent parts are relationally produced and inform the enactment of this hypermobile lifestyle. While this approach offers more nuanced understandings of the movement patterns, travel decisions and experiences of this lifestyle mobility, it does not fully attend to the social relations of lifestyle climbers as a community, which are an essential component of the performance of lifestyle mobilities. This process exposes an important attribute of lifestyle mobilities: while many travel as individuals, or in small groups, the performative 
nature of lifestyle mobilities generates community networks that span vast distances and that frequently also manifest in cyberspace.

\section{Lifestyle Mobilities}

The mobilities turn in the social sciences, argue Sheller and Urry (2006), calls attention to the ways in which people's daily lives are spatially connected. This includes the politics that drive (and hinder) the movement of people as well as objects, information and non-human things. But, perhaps more importantly, mobilities studies as an interdisciplinary field works to dismantle categorical boundaries of specific types of movement (tourism, migration, circulation and so on) and, instead fosters conversations that articulate the politics of (im)mobility (see Urry, 2002; Adey, 2006; Cresswell, 2006, 2010; Hannam, Sheller \& Urry, 2006; Hannam, 2009; Cresswell \& Merriman, 2011; Germann Molz, 2012; Merriman, 2013). In particular, Shubin (2010, p.517) argues, 'efforts to conform mobility to easily recognizable forms and stereotypes do not reflect the fluid and dynamic nature of ambulant lifestyles'.

It is for these reasons that Hannam (2009) suggests tourism may, in fact, be better approached as a specific process within a wider ontological context of mobilities. It is increasingly accepted that tourism is less 'an ephemeral aspect of social life that is practiced outside normal, everyday life' and is, instead, recognized as 'integral to wider processes of economic and political development and even constitutive of everyday life' (Hannam, 2009, p.106). But to say that tourism is a form of mobility only begins to hint at its relations, as different mobilities inform and are informed by tourism (Sheller \& Urry, 2006). Further, the definitional boundaries of tourism, in terms of duration of travel and dichotomous understandings of home/away, prove limiting when tourism is examined in 
isolation from other forms of mobility. The concept of lifestyle travel, thus, offers one example of the ways in which scholars have attempted to stretch the somewhat rigid designation of tourism. Lifestyle travelers, Cohen (2010, p.117) explains, are 'individuals for whom extended leisure travel is a preferred lifestyle that they return to repeatedly'. However, this is not a new phenomenon as these long-term travelers have also been referred to as 'lifelong wanderers' (Noy \& Cohen, 2005), 'contemporary drifters' (Cohen, 2004), and 'nomads from affluence' (Cohen, 1973) in the tourism literature.

Further engaging the mobilities paradigm suggests some lifestyle travel pursuits may be more thoroughly understood by examining the relations of travel, leisure and migration (Cohen, Duncan \& Thulemark, 2013; Duncan, Cohen \& Thulemark, 2014). Working from the broader notion of lifestyle mobility, Cohen et al. (2013) map the various ways mobile pursuits overlap, producing ways of life that are about being on the move (see also Urry, 2002). Indeed, the very fact that these are considered lifestyle pursuits suggests mobility has considerable implications for the ways in which these individuals find meaning in the world and construct a sense of identity. However, there are important distinctions between this form of mobility and temporary mobility, permanent migration and even seasonal migration, suggesting lifestyle mobilities, despite its diversity of manifestations, cannot be subsumed under these others. Lifestyle mobility is a sustained, ongoing process of semipermanent moves of varying durations, and is incorporated into everyday practices (Cohen et al., 2013). Yet, '[u]nlike permanent migration, lifestyle mobility does not pre-suppose that there is no intention to return ... [or that] ... there is no "one" place to which to return, and through time, there may be multiple "homes" that one can return to and/or revisit' (2013, p.4). There is also a distinction with seasonal migration, which exhibits more specific time periods and fixed timeframes that are typically rotational (see Thorpe, 2012). Lifestyle migration, also, has much in common with lifestyle mobility as it occurs among 'relatively 
affluent individuals [...] whose relocation is spurred by the belief that they can find a better way of life elsewhere' (Benson, 2011, p.224; see also Benson \& O'Reilly, 2009). While lifestyle migration is made possible by individuals' mobility socially, economically and globally, these migrants value the potential of future immobility of finding a place to settle down (Benson, 2011; Benson \& O’Reilly, 2009).

Lifestyle mobility is a combination of travel, migration and leisure (Cohen et al., 2013), with the latter factor so far rather absent from this discussion. Leisure proves crucial in distinguishing lifestyle mobilities. Whereas lifestyle travel finds individuals working to save money in order to return to traveling, lifestyle mobilities exhibit a stronger leisure component that is incorporated into travel patterns. From Boon's (2006) study of skiers who support their lifestyle pursuit through hotel employment at ski resorts to Duncan's (2008) research on budget travelers who work as they travel to Thorpe's $(2012,2014)$ transnational ethnography of snowboarders and action sport culture, the component of leisure is vital to travel decisions. Yet, such research also further blurs the distinctions between work and leisure for lifestyle mobilities as these tend to overlap, relate to and/or facilitate one another.

\section{Research Design}

Within the rock climbing community there are a number of subcultural identities relating to style of climbing (aid, traditional, sport, bouldering and others ${ }^{1}$ ), regional preferences, and degree of dedication to the sport - from leisure climbers who engage with the sport recreationally outside of other responsibilities to lifestyle climbers who hold parttime employment in order to support their full-time commitment to climbing to professional rock climbers who hold sponsorships from climbing corporations, thereby earning an income from their climbing. This research focuses on lifestyle rock climbers, as they 
exemplify a particular type of lifestyle mobility. As a subculture, these climbers exhibit a passionate dedication to the sport by maintaining minimalist, hypermobile lifestyles intended to prioritize rock climbing and the travel that accompanies it. While not professionals and not earning an income from their climbing, these climbers give up sedentary residences, living out of vans most commonly (Figures 1 and 2), as they travel between climbing destinations and take up temporary and/or Internet-based employment along the way. As a lifestyle sport mobility, lifestyle rock climbing is most commonly practiced in North America, as this region offers an abundance of rock climbing destinations all reachable by automobile travel. Nevertheless, this lifestyle mobility can be found globally, with many lifestyle climbers maintaining international travel circuits.

By their very nature, hypermobile communities are constantly in movement, with individuals traveling a variety of circuits and pathways, thus making them rather difficult to study (see D’Andrea, 2006; Merriman, 2013; Thorpe, 2014). Therefore, this research employed a mixed-method, multi-scale approach (see also Marcus, 1995). For grounded, qualitative investigation, it focused on one popular destination - Red River Gorge, Kentucky, USA - during its optimal climbing season. Because this is a popular destination for all types of rock climbers (leisure to lifestyle to professional), it was a useful site from which to observe and analyze subcultural differences. From September through November of 2011, I lived in 'The Red', observing and interacting with lifestyle climbers as they arrived for the season, moored for a few weeks to months, then departed for their next destinations. Time in this community resulted in a total of 21 interviews with lifestyle climbers: six females and 15 males. This gender disparity is representative of the lifestyle climber population observed at The Red, in which only about $30 \%$ were female. The age of participants ranged from 22 to 56 years, with the time spent pursuing lifestyle climbing ranging from six months to 17 years (see Table 1). These lifestyle climbers, as reflected in the rock climbing population in 
general, were predominantly white (Erikson, 2005). All but two of the interviewees were Americans, with the exception of one Canadian and one person from France. In terms of sexuality, two respondents self-identified as gay/lesbian.

\begin{tabular}{|c|c|c|c|}
\hline Gender & $\overline{\text { Age }}$ & Years rock climbing & Years as a lifestyle climber \\
\hline Male & Early 20s & 6 & 1 \\
\hline Male & Mid-20s & 5 & 1 \\
\hline Male & Mid-20s & 2 & 2 \\
\hline Female & Mid-20s & 8 & 2 \\
\hline Female & Mid-20s & 8 & 4 \\
\hline Male & Mid-20s & 6 & 3 \\
\hline Male & Late $20 \mathrm{~s}$ & 5 & 2 \\
\hline Female & Late 20 s & 10 & 3 \\
\hline Male & Late 20 s & 15 & 7 \\
\hline Male & Late 20s & 15 & 10 \\
\hline Male & Late 20s & 16 & 12 \\
\hline Female & Early $30 \mathrm{~s}$ & 2 & 1 \\
\hline Male & Early $30 \mathrm{~s}$ & 8 & 5 \\
\hline Female & Early 30 s & 9 & 7 \\
\hline Male & Early $30 \mathrm{~s}$ & 10 & 4 \\
\hline Male & Mid-30s & 4 & 1 \\
\hline Female & Mid-30s & 13 & 5 \\
\hline
\end{tabular}




\begin{tabular}{llll} 
Male & Mid-30s & 20 & 12 \\
Male & Late 30s & 10 & 6 \\
Male & Late 30s & 17 & 8 \\
Male & Mid-50s & 25 & 17 \\
\hline
\end{tabular}

\section{Table 1 - Demographics of Lifestyle Climbers at the Red River Gorge, Kentucky}

Considering the numerous identifiers and labels placed on this practice within the climbing community, I have chosen the term 'lifestyle climbers' in an effort to capture the diversity observed, while also relating to observations in the literature regarding lifestyle sport cultures (Wheaton, 2004; Thorpe, 2014), lifestyle mobilities (Cohen et al., 2013; Duncan et al., 2014) and lifestyle travel (Cohen, 2010a, 2010b, 2011). Yet, some of the more prolific self-identifiers should be noted: 'Dirtbag' is most commonly used as a way to connect individuals to a historical lineage and ideology of lifestyle climbing and travel in the rock climbing community. However, some do not self-identify as 'dirtbags', but prefer to be recognized as 'lifers' or 'full-timers' in order to express their commitment to the sport. Others, still, use 'vanner' so as to convey their minimalist lifestyle, travel mode and most common abode. Common to each of these is the notion that this is a lifestyle and that they are not professional rock climbers. Rather than choose of one these identifiers to classify this lifestyle mobility, 'lifestyle rock climbing' encompasses the sometimes-subtle differences among them.

Because it is difficult to define clear boundaries around particular subcultures in the rock climbing community, surveys were used to assess variations in travel behavior and patterns and commitment to the sport. These supplementary surveys extended across the 
rock climbing community, providing a larger population from which to determine subcultures of leisure climbers and lifestyle climbers. A total of 148 surveys were completed and analyzed, which represents an estimated $5-10 \%$ of the rock climbing population of The Red during the fall season. As part of the survey questionnaire, nearly 50 climbing destinations were listed, representing traditional, sport and bouldering climbing styles, with space for participants to record additional destinations. Participants were asked to indicate which locations have been visited, and the frequency and duration of visits. To establish some parameters, climbing destinations were limited to the contiguous United States.

Analysis also extended to the popular climbing website, Rockclimbing.com, and the local climbing website, Redriverclimbing.com, as well as climbing media (magazines, films, guidebooks and other websites). In an age of increasing globalization, social media can foster communities that span vast distances (Massey, 1991). So while climbers do meet and perform group identities on the ground, in specific locations, Internet forums facilitate community development and maintenance, as information about individual climbing destinations can be shared. Indeed, Altheide et al. (2008, p.135) suggest 'an ethnographic perspective can be brought to bear on symbolic communication in other than "physical spaces", including information bases and cyberspace' (see also Hine, 2008). Accordingly, discourse analysis of the online forums and climbing media provided insight into the social relationships and travel behavior that characterize this sport beyond the single location of grounded investigation.

\section{Towards a Politics of Lifestyle Rock Climbing}

In response to the growing popularity of a mobilities perspective, Cresswell (2010) is quick to point out that most of our mobile subjects exhibit long histories of mobility, which 
can be evidenced by interrogating their constellations of mobility. The constellations of mobility of lifestyle rock climbing are particularly significant as they illustrate historical context, social dynamics and forces of globalization at work across this itinerant community over time. Using Cresswell's six facets of mobility (motive force, route, velocity, rhythm, friction and experience), with the addition of turbulence (Cresswell \& Martin, 2012) and remove (Vannini, 2011), aids in fine-tuning an account of the politics of mobility. Moreover, interrogating one particular form of lifestyle mobility, lifestyle rock climbing, illustrates the relationality of such a deconstructive analysis. The very fact that this form of mobility has become a lifestyle pursuit suggests various social levels at which it functions and overlaps. Lifestyle mobilities are saturated with identity and community politics, that is, the merging of travel, migration and leisure is important to constructions and performances of identity individually and socially. A politics of mobility, however, does not fully account for the community aspects of lifestyle mobilities, but is an important starting point from which to investigate these social relations.

\section{Constellations of Lifestyle Climbing}

The mobilities turn in the social sciences may be better characterized as a return, suggests Cresswell (2010). Aiming to "dampen the enthusiasm for the "new" that characterises some of the work' (pp.26-27) in this field, he posits the concept of constellations of mobility as a way to illustrate that patterns, representations, and practices of movement are continuations of significant historical relations. So while the 'new' mobilities paradigm (Sheller \& Urry, 2006) foregrounds the ways in which our everyday lives are growing increasingly mobile, constellations of mobility reorient these mobilities within temporal, as well as spatial, contexts. Whereas lifestyle mobilities is a relatively recent conceptualization, lifestyle climbing is not a new phenomenon. Indeed, those climbers who 
prioritize the sport, making it a central focus of their lifestyle and travel, have a rich history within the rock climbing community.

Until WWII, the rock climbing community in the United States was primarily composed of climbing clubs, which organized recreational group outings. While these were male-dominated organizations, women frequently participated as well. However, following the war, this changed drastically. The 1950s, Taylor (2010) argues, brought the 'individualists' and the 'experientialists' to the fore. These climbers began venturing onto rock faces alone or in small groups outside the organization of clubs, and in so doing, they pushed the limits of what was considered climbable. The Beatnik climbers of this generation engaged a countercultural quest for experiences and are noted for bringing the elements of travel and climbing together (Taylor, 2010, p.131; Mellor, 2001). Among the first to turn climbing into a lifestyle was Mark Powell, who in the 1950s began a seasonal rhythm of winter working, saving money and training in Los Angeles, followed by a move to Yosemite for climbing spring through fall. This prioritizing of rock climbing as a lifestyle revolutionized the sport and the potential of the climbing body. By the late 1950s, Powell was 'simply the best', and Taylor (2010) identifies several commonalities among this early lifestyle climbing community that set them apart from previous generations:

These communities were filled with loners and outcasts by chance and design. [...] More common were some very well-educated young men rebelling against a world that had groomed them. Nearly all attended college, most had degrees, and a few were in graduate school before choosing climbing instead. As in the past, Beats embraced the sport as a way to construct the self. (p.138)

Undeniably, these were male-only communities. Women had little place in this rock climbing culture, and those who attempted entry were met with contempt, as well as symbolic violence. According to Taylor (2010, p.142), through the 1960s, '[b]eyond sex women were often afterthoughts [...] [they] represented a threat to the gang' domestically and as fellow 
climbers. From verbal abuse to ostracizing female climbers, there were also rare instances of sabotage of women's climbing gear and camping equipment.

By the late 1960s and into the 1970s, the social scene of the rock climbing world had evolved so that the Beats were the 'elders' and they viewed the next generation, the 'dirtbags', as 'arrogant', 'vulgar', lacking commitment and overindulgent in everything from poverty to drugs (Taylor, 2010). Yet, it is the 'dirtbag' generation that is credited with the discovery of new climbing areas and broadening travel circuits while simultaneously fashioning more specific climbing styles, techniques and gear. By this time, more women had scratched out a place for themselves among this community of lifestyle climbers, but they were few and their positions were constantly tenuous.

The greatest increase in female climbers has been witnessed since the early 1980 s. Lynn Hill is credited with making significant strides for women in rock climbing. By the late 1980s she sat among the top professional climbers, with lucrative sponsorships. Through the 1980s-90s, rock climbing as a recreational activity continued to grow in popularity, and so did the idea of taking up the sport as a lifestyle. The professional climber was born out this generation, as climbing gear and media companies were established and expanded. Professional climbers continue to be hypermobile in pursuit of rock climbing year-round; however, corporate sponsorships fund their lifestyle but also require these athletes to participate in media appearances and climbing competitions (see Taylor, 2010; Thorpe, 2014). While still a minority overall, female climbers hold a numbers of positions among the top climbers in the world, and likewise, their presence among lifestyle climbers is growing as well.

For these later generations of lifestyle climbers, travel circuits have become more established and well-known. While new destinations are still being 'discovered', historically significant places remain iconic and climbing at them can be used as social capital. More 
contemporary generations of traveling climbers are further aided by the proliferation of global telecommunications. While many take up temporary employment in the various destinations at which they moor, Internet-based employment is increasingly favored as more flexible and reliable. Indeed, a laptop and Wi-Fi signal is all that most need to continue to earn a paycheck on the road, and many destinations offer Internet, either at the campground or it can be accessed at local businesses. Moreover, online forums now offer a new means for communication and community cohesion.

As this lifestyle has persisted in the climbing community it has become a historically extant subculture, referred to most generally as 'dirtbags', although many do not self-identify as such. Indeed, the 'dirtbag' identity comes with much baggage, exemplifying this history. While some leisure climbers look upon this lifestyle favorably as a passionate dedication to the sport they love as well, others fear it fosters a bad reputation for all climbers, as dumpster-diving, illegal parking/camping and minimalist lifestyles (or 'poverty') are regularly practiced. Thus, lifestyle climbers, because of their historical and spatial relationship to the 'dirtbag' identity, carry with them these associations, from within and outside the climbing community, whether they define themselves as dirtbags or not.

\section{A Politics of Lifestyle Climbing}

When analyzing the politics of lifestyle rock climbing, one could choose to elaborate on any of the six constituent parts of mobility advanced by Cresswell (2010). I aim to work through all of them, thereby illustrating the varying degrees of import of each facet for this form of lifestyle mobility. Incorporating additional elements - turbulence (Cresswell \& Martin, 2012) and remove (Vannini, 2011) - theorized by more recent scholarship further highlights the contextuality of particular forms of mobility. Particularly significant to lifestyle mobilities are the communities that form as a result of hypermobility. Thus, in working through the 
facets of mobility attention has been paid to address the implications of each for lifestyle climbers as a community.

In the case of lifestyle rock climbing, perhaps the most obvious question to begin with is: Why? This is what lifestyle climbers are most frequently asked by family, friends, coworkers and even strangers - Why do you want to do this? - referring to their decision to give up more sedentary lives and careers for hypermobile lifestyles. More specifically, most who inquire are also making reference to their mobile abodes - a van, most commonly, but some also live out of a RV, a car or simply a pack. Cresswell $(2010, p .22)$ asserts that motive force addresses the question, 'why does a person or thing move?', and he adds that for humans this is further complicated by both internal and external forces. The most repeated response by these climbers is that they want to rock climb as much as possible, which necessitates travel and a mobile lifestyle. Put simply, 'there's nowhere that is great 12 months of the year, so if you really want to climb all the time, it's pretty important [to travel]' (Male, late-20s, lifestyle climbing for 10 years). Yet, further investigation of motive force reveals a series of motivations that extend well beyond the proverbial rock face to notions of identity, existential crisis, social pressures and relationship problems (Rickly-Boyd, 2012, 2014; see also Thorpe, 2012, 2014). That is, most described both push and pull factors of motive force.

In speaking with lifestyle climbers, motive force was also among the first questions I raised and received rather straightforward responses in terms of rock climbing as a motivation. But as my inquiries continued, in particular by asking about likes and dislikes related to living mobile lifestyles, explanations quickly shifted from rock climbing to notions of identity, community and the ways they want to live life. The following example illustrates existential crisis and one of the most dramatic shifts in self-image encountered in this fieldwork. For this lifestyle climber, life in general was bland. Even though she was climbing 
recreationally, she found the atmosphere of daily life unbearable and lacking drive. The decision to travel and rock climb full-time prioritized her decision making, it offered focus and purpose, even if she only plans to live this way for a few years in order to 'figure things out':

I feel complete. I was pretty lost before I started climbing; it saved me, in many ways. I don't like driving several hours just for work, I don't like being in a cubicle, to, like, be in there to work eight hours, 8 to 5, in an office. I did that for a while. It didn't interest me and I didn't have an appetite, for anything, really. I was like 20 pounds lighter, addicted to Adderall [a medication used for attention deficit hyperactivity disorder]. (Female, mid-20s, lifestyle climbing for 2 years)

Similarly, others expressed a number of push and pull factors that led to their decision to take up lifestyle climbing. For some it was rather simple, having finished university and unsure what to do next in terms of career path, they chose to take a few years off, to travel and rock climb, and assess their goals. Others describe slower processes of transition, from spending every weekend traveling for climbing to taking a few weeks and months off of work to making rock climbing a full-time commitment. These differences in approach also illustrate the spectrum of lifestyle travel to lifestyle mobilities. Indeed, those who fall under the latter description were also more likely to state that they intend this to be a lifelong pursuit, not a temporary endeavor with an end goal of selfdiscovery or a path to making an important life decision.

To me it's not just, like, a transition, it's a choice. And, it's my life. I'm not on vacation. It's my life, so I'm going to try to stick with it as long as I can. (Female, early 30 s, lifestyle climbing for 5 years)

Investigating the conditions of lifestyle rock climbing in terms of motive force, however, does not fully address lifestyle climbing as a form of lifestyle mobility and thereby necessarily brings into conversation the facets of route, velocity and rhythm in nearly disentanglable ways. The deceptively simple question of motive force for lifestyle climbing is thus much more complicated; why a person or thing moves, should also be considered within the conditions that produce and are produced by lifestyle climbing. 
Lifestyle climbers travel in circuits in which climbing destinations function as nodes. These are informed by climbing preferences (aid, sport, traditional or bouldering), seasonality, and personal circumstances (monetary resources, transportation mode, etc.). As such, climbers' circuits vary in terms of flexibility and rigidness of itinerary. Whereas some travel to the same locations year after year at distinct times, others have few repeated patterns.

Last couple of years, my schedule has been The Red all season [spring to fall], go to Squamish [British Columbia, Canada] in the summer for at least a month, I fly usually because it's just too far, too expensive. After Thanksgiving I usually move to Chattanooga [Tennessee] for December, then to Hueco Tanks [Texas] for January, February. (Male, late-20s, lifestyle climbing for 7 years)

Further, there are some climbers who prefer to spend the majority of the year in one location, with only short trips to other destinations during the most inclement times of year. For example, there are a handful of lifestyle climbers who moor in the Red River Gorge for about nine months of year, traveling only regionally July-August and January-February. Despite living out of vans and RVs, their notions of community and home are more grounded in place than other itinerant climbers. Interestingly, these lifestyle climbers maintain the potential of mobility, while in actuality mooring most of the year. Explained one such climber,

I like it here. I like the climbing here. I don't really see the need to go to a bunch of different places all the time. (Male, late-20s, lifestyle climbing for 12 years)

Mobility is channeled along routes. Cresswell (2010, p.24) argues, '[i]t does not happen evenly over a continuous space'. Indeed, lifestyle climbers do not simply move between climbing destinations, but various factors push even those of similar inclinations in different directions and along divergent pathways, overlapping in sometimes unpredictably. In this way, the location in which this research with lifestyle climbers was conducted is especially important. While The Red is among the top sport climbing destinations in the 
world, it offers less traditional climbing or bouldering. As such, it is virtually excluded from the circuits of climbers with those specific interests.

Surveys of the overall climbing community in the Red River Gorge were used to tease out differences in travel patterns and behavior between lifestyle climbers and leisure rock climbers. As Figures 3 and 4 indicate, climbers who visit The Red in the fall season also visit similar climbing destinations across the United States. However, lifestyle climbers visit these destinations with much greater frequency than leisure climbers as a result of their mobile lifestyles. These data also reveal the regionality of this fieldwork. While West Coast climbing destinations are among the oldest and most well-known in the climbing community, they are less frequently visited by participants in this study than Appalachian climbing destinations. This illustrates a distance-decay relationship that is further supported by analysis of online forums, analyzed in order to better capture the breadth of the climbing community, which demonstrate that West Coast climbing destinations are more represented among conversational threads than they appear in these survey results.

These disparities were also revealed in interviews with climbers who identified a number of regional circuits, and how they grow and change with time. In addition to route, the following quote also illustrates the facet of velocity. 'How fast does a person or thing move?' suggests hierarchies of mobility (Cresswell, 2010, p.23). For lifestyle climbers, speed of movement between destinations varies depending upon monetary resources and mode of transportation. The velocity with which one moves may place limitations on which routes destinations are possible; those moving more slowly by hitching rides may be able to visit fewer destinations as their travel is dependent upon others.

For us [male and female pair], I think we did kind of a new circuit this year in that it hasn't really become a very popular circuit yet, because Tensleep [Wyoming] hasn't blown up. But, you know, The Red is now the new, awesome place to be in October. And the West Coast circuit during the winter, where you start in, like, Squamish [British Columbia] then to Smith Rock [Oregon] to Yosemite [California] to Bishop [California] to possibly Tahoe [California] to Red Rocks [Nevada] 
to Hueco Tanks [Texas] to Tahquitz [California] and then right back up the coast again. [...] I guess the West Coast circuit is probably the one that is the most engrained in the dirtbag, like, migration pattern. [...] And, I guess there is kind of a Red [River Gorge] circuit, but it only happens with like the local Red people. You get people staying at The Red all summer, and, like, going to the New [River Gorge, West Virginia] to stay cool sometimes, and going to the Obed [Tennessee] to stay cool and then in the winter people go down to T-Wall [Tennessee]. People don't really live at Horse Pens [Alabama], but they'll go bouldering there anyhow, and Little Rock City [Tennessee] and Rocktown [Georgia]. Then spring they'll be back at The Red. It's a smaller circuit and it's certainly not as linear as the West Coast, but since the Red has become such a huge climbing mecca, it's starting to develop its own circuit slowly, I think. (Female, mid-20s, lifestyle climbing for 4 years)

This quote also draws attention to rhythm. 'Rhythms are composed of repeated moments of movement and rest'; thus asking, '[i]n what rhythm does a person or thing move?' (Cresswell, 2010, p.24), is a way of assessing social worlds that collide, overtake and/or interrupt in and across places. Considering the history of lifestyle climbing, reveals it once exhibited a very different travel rhythm. Its earliest manifestations arose with clearly defined, small and exclusive West Coast travel circuits. As the climbing lifestyle gained popularity in the 1960s, most climbers followed similar travel circuits resulting in familiar faces at most destinations. Particular rhythms of mobility were more pronounced, describes Taylor:

It was a tightly knit yet fluid society, with members coming and going through the year: spring in Yosemite and the Southwest, summer in the Tetons, Rockies, and Alaska, and fall back in the Valley. (2010, p.140)

Contemporarily, lifestyle climbers exhibit an immeasurable variety of climbing styles, motivations and travel modes that result in highly individualized circuits. Nevertheless, many describe the ways in which their travel circuits continue to overlap with others' in both predictable and surprising ways. Whereas routes and velocities of movement, and as a result rhythms vary, intersections of individual circuits still occur with great frequency. While most relayed stories of encounters in surprising locations, including literally bumping into an old friend in a campground in France (Male, mid-30s, lifestyle climbing for 6 years), they also observed the consistency of the community more generally: 
Nobody really, like, dwells on like the whole goodbye thing in this community, because everybody's always around. You say goodbye to somebody, and they're like, "I'm sure l'll see you in the next year or so". (Female, mid-20s, lifestyle climbing for 2 years)

While rock climbing is the primary motivator of this lifestyle and thereby most individual's travel decisions, there are many other tangential factors that may cause turbulence in travel itineraries. Turbulence, suggest Cresswell and Martin (2012, p.526), deserves greater consideration in mobility studies - 'To more fully understand mobility and to properly delineate a politics of mobility we need to take the "event" of unpredictable mobility seriously'. That is, mobility is not simply ordered, or disorderly, rather, '[w]hat we make of turbulence depends very much on our investment in the kinds of orderings that turbulence allegedly makes untenable. To some, turbulence is a threat and to others an opportunity' (2012, p.518). Indeed, lifestyle climbers live in a world of frequent turbulence, particularly relating to their monetary resources. Most live on strict, minimalist budgets so that any extra expenses may hinder travel. From vehicle maintenance to health issues, savings are small and quickly drained.

During my time in The Red, I regularly spoke with one climber as he grew despondent about his financial situation. Having lived on the road for more than 10 years, he was growing weary of relying on temporary employment. When his car broke down, resulting in a repair bill that was beyond his financial means, he quit climbing and went in search of full-time employment and an apartment. Of course, the repair bill was not the sole reason for his decision to change his lifestyle; it was simply the last straw, so to speak. Leading up to this decision, he had spoke about a loss of passion for a full-time dedication to the sport, questioning how much longer he would maintain this lifestyle (predicting another year or two), and he explained that the community was changing and he no longer felt he belonged as he once did. Thus, in this case, turbulence created friction, being one of 
the factors that answers the question, 'When and how does it stop?' (Cresswell, 2010, p.26). But the turbulence of unexpected and unaffordable expenses did not act in isolation, it fed upon other feelings of discontent to create friction. This is particularly evidenced by the fact that most lifestyle climbers will experience similar moments of turbulence, and while it might slow their travel, it does not always halt it.

Thus, turbulence must not always be conveyed as negative. In another instance, one climber described her international travel circuit. But as we spoke she was making new travel plans and was uncertain where the following months and years would take her. She had been traveling in the United States for several years by annually obtaining a tourist visa. With her application for a green card approved, she was allowed to stay for as long as she wished. This turbulent event brought new opportunities:

I fell in love with The Red, which was all the trigger for trying to get a green card and come back. So I was climbing with a six-month visa, a tourist visa. I was spending from spring to summertime in the U.S., then I was going back to France and what l've been doing is going to Thailand in wintertime, then Greece, Kalymnos, in March, then coming back. That was kind of my circuit until now. But this green card has changed a lot of things. (Female, mid-30s, lifestyle climbing for 5 years)

The discussion so far has moved through the facets of motive force, route, velocity, rhythm, friction and turbulence of lifestyle rock climbing. But Cresswell (2010, p.25) also asks, 'How does it feel?' The experience of mobility for lifestyle climbers, like the other facets, is a complex assemblage of highs and lows. While most lifestyle climbers affirmed that a minimalist, hypermobile lifestyle is simpler, compared to work and relationship stress, and family responsibilities, simple does not mean easy. In fact, most expressed that they have been surprised by just how difficult daily life on the road can be, and in rather unexpected ways. Lifestyle climbers experience a good deal of downtime, and much of the day is spent trying to fill hours of 'empty' time. While, indeed, they do spend considerably more time rock climbing, with nearly daily opportunities to get on the rock face, only so 
much time can be spent climbing. Whether physically limited by the resilience of one's body, which needs time to rest and recover, or limited by temporary weather conditions, lifestyle climbers find a significant portion of their time is spent off of the rock face. Because of minimalist budgets, they can afford few recreational activities in-between. In the following quote a climber describes the difficulties, the moments of existential angst when climbing is not possible, and the rewards of lifestyle climbing when it is. Indeed, lifestyle climbers frequently question the motive force of this lifestyle choice in terms of existential goals, that is, in the way they should be living their lives for the greatest fulfillment.

It's quiet. People disperse, you know, anything and everything to keep your mind occupied so you're not thinking about not being able to go rock climbing. You sleep a lot, drink in the afternoon, whatever. [...] I mean, every now and then you have those days, where it's rainy and it's fucked and everything you have is wet and it's cold and it's shitty. And you're just like, "what the fuck am I doing living in the woods, man?" I could be doing be something with my life, I could be giving something back to society. But no, I'm going to live in my car and get rained on so I can go rock climbing tomorrow. But, then, when the sun comes out and the rock's dry and you do that first pitch, you remember why you're doing it. (Male, early 20 s, lifestyle climbing for 2 years)

So far this analysis of the politics of lifestyle rock climbing as been general, yet focusing on the facet of experience, and the ways in which it relates to motive force, implicates a more explicit discussion of the gender politics of this community. As outlined in the above description of constellations of lifestyle climber mobility, from its beginnings lifestyle climbing has been male-dominated, with symbolic violence against potential female members of the community. Taylor (2010) provides a number of examples of the verbal abuse endured by female climbers in the 1950 s- 70 s as they attempted entrance to the community, as well as accounts of sabotage of the women's climbing gear, used as scare tactics but with life threatening consequences. Such blatant and violent sexism is rare today, but the undercurrents of misogyny remain. This is true of the sport as a whole, as the work of Frohlick (2005), Chisholm (2008), and Robinson (2008) have illustrated in analyses of rock climbing media and community dynamics. So while many of the male interviewees 
were quick to point out the rise of female rock climbers within the sport, they were more hesitant to embrace female lifestyle rock climbers. Indeed, the following was a common rebuttal in regards to women rock climbers:

Girls kick ass at this sport. They're actually a lot better than we [men] are at it. Their flexibility and balance is way better, they're doing completely new things up there. (Male, late-30s, lifestyle climbing for 6 years)

Yet, when asked about women who pursue the sport as a form of lifestyle mobility, male interviewees expressed that they were 'impressed', that is, they were surprised that women are able to 'keep up with the guys [...] because life is hard on the road' (Male, late30s, lifestyle climbing for 6 years). So while one can witness changes in perceptions of gender in the rock climbing community, generally, male lifestyle climbers continue to place restrictions on the capabilities of female climbers who travel for the sport.

As such, it is important to consider female lifestyle climbers' experiences, specifically, and indeed they were happy to discuss this aspect of their mobile lifestyles. As the following quote suggests, women are well aware of the gendered perspectives that accompany rock climbing and the ways in which those perspectives are performed in the community. And most noted that they have adapted by paying little mind to the attitudes and subtleties of misogyny that are pervasive.

That's rock climbing. We can say whatever we want; it's pretty sexist, still. It's kind of a boys club. But it's more and more the girls are kicking the boys, you know, especially at The Red. [...] Let's face it, it's a male environment, for sure, but the momentum, that is changing slowly but surely, but yeah more males, which is, I'm not going to complain about that (laughing). That's not always a bad thing, you know, if you get a little lonely sometimes. (Female, mid-30s, lifestyle climbing for 5 years)

Nevertheless, it is worth noting that in observations of the lifestyle climber community at The Red, there were are fewer single female climbers than male climbers. Regardless of sexual orientation, the vast majority of female lifestyle climbers were partnered, from serious relationships to more promiscuous arrangements. In fact, several 
cited their mobility as a means to find new relationships, and to keep them informal, whereas many of the male lifestyle climbers interviewed noted the difficulty of finding a partner in this community, which led to loneliness as a factor of the experience of lifestyle mobility.

Another important aspect of the experience of lifestyle climbing is that it very often takes climbers to out-of-the-way locations. Most climbing destinations are in or near wilderness areas, and as a result, climbers camp at isolated sites or small campgrounds, with few places offering larger campgrounds that afford a space of social gathering. Thus, Vannini's (2011, p.252) addition of remove to the facets of mobility is quite applicable to lifestyle climbing. Remove relates to experience and route, but it is distinct. It is subjective and practical, a noun and a verb; it is 'intended to highlight what people do to separate or connect' (2011, p.252). As such, remove yields insulation and isolation.

For lifestyle climbers, isolation and insulation are intertwined. While giving up sedentary careers and residences for mobile lifestyles isolates them from contemporary, urban society it also contributes to stronger, insular, albeit spatially diffuse communities that come together in out-of-the-way locations. As explained in the quote below, the community of lifestyle climbers is small and exclusive, but traveling in circuits that overlap with others' itineraries repeatedly brings them together. As such, lifestyle climbers use distance to remove themselves from broader social relations, but in so doing, they are brought into closer proximity with other lifestyle climbers.

I like the independence. Also, I like the community. So, I like both. I feel like I have my own little world in the middle of this community, which is super nice for me. It's a great compromise. I don't feel committed to staying in a house that I bought, with a mortgage, and a job. I don't feel stuck. I like that. And, there's no other way I could do it and see my climbing family, because they're all doing the same thing. So part of the reason I go to Hueco [Texas] every year is because I have people that l've known for a super long time that do the same thing. So it's like a family reunion. [...] I don't know that many people who don't climb, I mean, it's my whole life. I've been climbing longer than I haven't. (Male, late-20s, lifestyle climbing for 7 years) 
Thus, the fieldwork site of this research is, again, important as it exemplifies the ways that remove yields isolation and insulation, not just as a dynamic of a mobile community, but in the grounded performances of lifestyle climbing. While many of the world's best rock climbing destinations offer little if any accommodations beyond small campgrounds, The Red is among the few that boast an extensive and lively social scene. The heart of this community is Miguel's Pizza. Opened in the mid-1980s by an immigrant from Portugal, this site is home to an eclectic mix of travelers in the heart of Appalachian Kentucky. Indeed, the two flourish together. The rural poverty and inaccessibility of the Appalachian Mountains has contributed to isolated and insulated communities, and unfortunately, at times breeds contempt for outsiders. This is what Miguel Ventura encountered when he first set up shop in an area in which he foresaw potential economic growth, as it is adjacent to state and national parks. But few tourists or locals patronized his establishment; rock climbers, on the other hand, flocked there. In the 1980s, The Red was still a relatively unknown rock climbing destination. But the small community of local, regional and lifestyle climbers interested in exploring undeveloped climbing areas began to visit, and Miguel's Pizza became the central point of camping, socializing, and dining.

In the beginning, the pizzeria had parking for only a handful of vehicles, a dozen camping spots and the shop itself could host few more. By the early 1990s, as news of The Red - the newest and potentially best sport climbing area in the country - spread through the larger rock climbing community, Miguel's grew tremendously, expanding its camping accommodations several times over and adding a gear shop to the establishment. Miguel's Pizza has been featured in all the major climbing magazines and the Venturas are now a prominent business family in the region. Today the property can accommodate nearly 500 campers, with Wi-Fi and large restroom, shower, and laundry facilities at a rate of just $\$ 2$ per day per camper. In fact, the area has become so popular that during its peak climbing 
season, October to November, climbers spill out to other campgrounds that have opened in recent years to cater primarily to this community. During this time, one can easily hear dozens of different languages spoken, as climbers travel from all over the world to this small, isolated community.

Yet, while most of the climbers that travel here are leisure climbers, visiting for a few days to weeks, this situation is emblematic of the social scenes in which lifestyle climbers continually find themselves, or hope to. That is, while social scenes such as this do exist in other places, often there is no social scene at all, just a campground with enough space for a few tents. The promise of community informs travel behavior, as it becomes one of the factors which influences travel patterns (see above quote). It is not surprising, then, the fondness with which lifestyle climbers spoke about The Red. While many noted that it is primarily the style and quality of rock climbing that draws them here, the social scene was also frequently described as special, as something that cannot be found in all destinations in which they moor. As a result, several climbers described feeling homesick more often when they are climbing in places that lack a social space. So while their lifestyle mobility removes them from many of their grounded social networks, it also fosters isolated, yet insular, communities that are at the same time ephemeral. Further, while such places are transitory for lifestyle climbers, they are quite grounded and permanent for the local residents who live and work in the region.

In working through Cresswell's facets of mobility, with the additions of turbulence and remove, a politics of lifestyle rock climbing become more nuanced. None of the constituent parts can be understood alone, but each is related to the others in necessarily complex ways. This is why, as Cresswell (2010) states, mobility works in constellations of pattern, representation and practice. However, there is much that is left unattended to when applying this framework to a form of lifestyle mobility. The very fact that this is a lifestyle 
pursuit extends the scale of social relations to the politics and performance of community.

This analysis has aimed to attend to a finer scale by extending each of the facets of mobility to their implications on lifestyle rock climbers as a hypermobile, ephemeral community. This, I would argue, is particularly important for conversations of the politics of lifestyle mobilities, as this form of mobility, even if undertaken by individuals or small groups, fosters communities that are both grounded and spatially diffuse and frequently also exist in cyberspace.

\section{Conclusion}

The mobilities paradigm is offering innovative, interdisciplinary perspectives on familiar, as well as unfamiliar, forms of mobility. A central interest of this field of study is the perspective that mobility is movement that is constituted by patterns, representations, and practices (Cresswell, 2010). Indeed, Shubin (2010, p.495) states mobility is 'a process through which space and society come into being'. This statement is particularly salient in regards to lifestyle mobilities, and the case of lifestyle rock climbing in particular. The practice of lifestyle climbing produces particular social relations, internally and externally. That is, there are distinct community patterns, practices and representations that are produced by full-time, traveling rock climbers as a result of their individual and collective practices, and which means that some social relations with more urban and/or sedentary society are altered.

While this form of lifestyle mobility has more recently garnered academic attention, it is not a new mobility. Indeed, recounting the constellations of mobility for lifestyle climbers traces a historical trajectory that changed with the larger rock climbing community, growing global telecommunications, and greater emphasis on individuality in American culture. Further, assessing the politics of lifestyle climbing offers a methodological and 
mesotheoretical approach to tease out the nuances that drive and hinder this lifestyle mobility. By working through each of the facets of mobility, the complexity of the social relations and personal circumstances of lifestyle climbers are uncovered. Yet, despite this complexity, patterns are discernible in terms of travel behavior, specifically in regards to routes and rhythms, and more importantly, the social relations that inform these patterns, and are informed by them, are highlighted.

Yet, working through these facets towards a politics of lifestyle mobilities further suggests the importance of considering community dynamics. Lifestyle mobilities foster communities, in specific locations where individual circuits overlap, with spatially diffuse notions of belonging and identity, and also frequently manifest in cyberspace. Community has implications for each of the facets of mobility posited by Cresswell (2010), but to assess these implications one must push beyond the surface of the questions posed by each. This is an essential component to the study of lifestyle mobilities, as their associated constellations of mobility are not isolated, ahistorical endeavors but they have distinct social relations internally and externally to the community. Working from a politics of mobility to further interrogate lifestyle mobilities offers a worthwhile framework for analysis, as it presents a more fine-tuned set of analytics but also leads one to both deeper and broader questions of social relations, cultural processes, power structures and ethical considerations. Only aspects of these broader questions are addressed in this paper, but these issues point in the direction of important future research regarding lifestyle mobilities.

\section{Acknowledgements}


This paper was presented at the 2014 AAG Annual Conference in Tampa, Florida. I would like to thank the reviewers for their constructive critique and thoughtful comments. Further, I wish to extend my appreciation to Lisa Braverman and Daniel Knudsen for their insights on earlier drafts of this paper. Any remaining errors are the sole responsibility of the author.

\section{Notes}

${ }^{1}$ One of the fundamental divides in rock climbing is between aid climbing and free climbing. Whereas free climbing means only hands and feet are used to propel the climber up the route (the rope, harness and other gear are used only as protection in case of a fall), aid climbing places gear (stirrups, ladders, slings) by which the climber ascends the rock face. Free climbing is further divided by several styles - traditional climbing, sport climbing and bouldering, most prominently. In traditional climbing temporary protective gear (cams and nuts) are placed in natural rock features (usually cracks) by the lead climber and removed as the second climber ascends. Sport climbing developed in areas where, because of the type of rock or overhanging cliff lines, traditional climbing was not possible. So, as opposed to traditional climbing, it utilizes permanently placed protection, usually bolts that have been drilled into the rock. Bouldering, then, takes place within a shorter distance from the ground so that no ropes are used, just a 'spotter' and 'crash pads' for landing. 


\section{References}

Adey P. (2006) If Mobility is Everything Then it is Nothing: Towards a Relational Politics of (Im)mobilities. Mobilities 1: 75-94.

Altheide D, Coyle M, DeVriese K, et al. (2008) Emergent Qualitative Document Analysis. In: Hesse-Biber SN and Leavy P (eds) Handbook of Emergent Methods. New York: The Guilford Press, 127-151.

Anderson J and Erskine K. (2014) Tropophilia: A study of people, place and lifestyle travel. Mobilities 9: 130-145.

Benson M. (2011) The Movement Beyond (Lifestyle) Migration: Mobile Practices and the Constitution of a Better Way of Life. Mobilities 6: 221-235.

Benson M and O'Reilly K. (2009) Lifestyle Migration: Expectations, Aspirations and Experiences. In: Kershen AJ (ed) Studies in Migration and Diaspora. Burlington: Ashgate.

Caton K. (2012) Taking the moral turn in tourism studies. Annals of Tourism Research 39: 19061928.

Chisholm D. (2008) Climbing like a Girl: An Exemplary Adventure in Feminist Phenomenology. Hypatia 23: 9-40.

Cohen E. (1973) Nomads from Affluence: Notes on the Phenomenon of Drifter-Tourism. International Journal of Comparative Sociology 14: 89-104.

Cohen SA. (2011) Lifestyle Travellers: Backpacking as a Way of Life. Annals of Tourism Research 38: 1535-1555.

Cohen SA, Duncan T and Thulemark M. (2013) Lifestyle Mobilities: The Crossroads of Travel, Leisure and Migration. Mobilities.

Crang $M$ and Zhang J. (2013) Transient dwelling: trains as places of identification for the floating population of China. Social \& Cultural Geography 13: 895-914.

Cresswell T. (2006) On the Move: Mobility in the Modern Western World, London: Routledge.

Cresswell T. (2010) Towards a politics of mobility. Environment and Planning D: Society and Space 28: 17-31.

Cresswell T and Martin C. (2012) On Turbulence: Entanglements of disorder and order on a Devon beach. Tijdschrift voor economische en sociale geografie 105: 516-529.

Cresswell T and Merriman P. (2011) Introduction: Geographies of Mobilities - Practices, Spaces, Subjects. In: Cresswell T and Merriman P (eds) Geographies of Mobilities - Practices, Spaces, Subjects. Burlington, VT: Ashgate, 1-18.

D'Andrea A. (2006) Neo-Nomadism: A theory of post-identitarian mobility in the global age. Mobilities 1: 95-120.

Duncan T, Cohen SA and Thulemark M. (2014) Lifestyle Mobilities and Corporealities. Aldershot, Hampshire: Ashgate Publishes.

Frohlick S. (2005) "That playfulness of white masculinity': Mediating masculinities and adventure at mountain film festivals. Tourist Studies 5: 175-193.

Germann Molz J. (2012) Travel connections: Tourism, technology and togetherness in a mobile world, London: Routledge.

Hannam K. (2009) The End of Tourism? Nomadology and the Mobilities Paradigm. In: Tribe J (ed) Philosophical Issues in Tourism. Bristol: Channel View Publications, 101-113.

Hannam K, Sheller M and Urry J. (2006) Mobilities, immobilities and moorings. Mobilities 1: 1-22.

Hine C. (2008) Internet Research as Emergent Practice. In: Hesse-Biber SN and Leavy P (eds) Handbook of Emergent Methods. New York: The Guilford Press, 525-541.

Kabachnik P. (2012) Nomads and mobile places: disentangling place, space and mobility. Identities: Global Studies in Culture and Power 19: 210-228.

Lefebvre H. (2004) Rhythmanalysis: Space, Time and Everyday Life, New York: Continuum. 
MacCannell D. (2011) The Ethics of Sightseeing, Berkeley, CA: University of California Press. Massey D. (1991) A Global Sense of Place. Marxism Today: 24-29.

Mellor D. (2001) American Rock: Region, Rock, and Culture in American Climbing, Woodstock, VT: The Countryman Press.

Merriman P. (2013) Rethinking Mobile Methods. Mobilities.

Mostafanezhad, M., \& Hannam, K. (Eds.). (2014). "Moral Encounters in Tourism." Honolulu: Ashgate Press.

Noy C and Cohen E. (2005) Introduction: Backpacking as a rite of passage in Israel. In: Noy C and Cohen $\mathrm{E}$ (eds) Israel Backpackers and their Society: A View from Afar. Albany, NY: State University of New York, 1-43.

Rickly-Boyd, J. M. (2012) Lifestyle Climbers: Towards Existential Authenticity. Journal of Sport \& Tourism, 17, 85-104.

Rickly-Boyd, J. M. 2014. "Dirtbags": Mobility, Community and Rock Climbing as Performative of Identity. In Lifestyle Mobilities and Corporealities, eds. T. Duncan, S. A. Cohen \& M. Thulemark, 51-64. Aldershot, Hampshire: Ashgate Publishers.

Robinson V. (2008) Everyday Masculinities and Extreme Sport: Male Identity ad Rock Climbing, Oxford: Berg.

Sheller M and Urry J. (2006) The new mobilities paradigm. Environment and Planning A 38: 207-226.

Shubin S. (2011) "Where Can a Gypsy Stop?" Rethinking Mobility in Scotland. Antipode 43: 491-524.

Taylor JE. (2010) Pilgrims of the Vertical: Yosemite Rock Climbers \& Nature at Risk, Cambridge: Harvard University Press.

Thorpe H. (2012) Transnational Mobilities in Snowboarding Culture: Travel, Tourism and Lifestyle Migration. Mobilities 7: 317-345.

Thorpe H. (2014) Transnational Mobilities in Action Sport Cultures. Palgrave Macmillan.

Urry J. (2002) Mobility and Proximity. Sociology 36: 255-274.

Vannini P. (2011) Constellations of ferry (im)mobility: islandness as the performance and politics of insulation and isolation. Cultural Geographies 18: 249-271.

Vannini P and Taggart J. (2012) Off-grid Mobilities: Incorporating a way of life. Transfers 2: 1031

Wheaton, B. 2004. Introduction: Mapping the Lifestyle Sport-Scape. In Understanding Lifestyle Sports: Consumption, Identity and Difference, ed. B. Wheaton, 1-28. London: Routledge. 


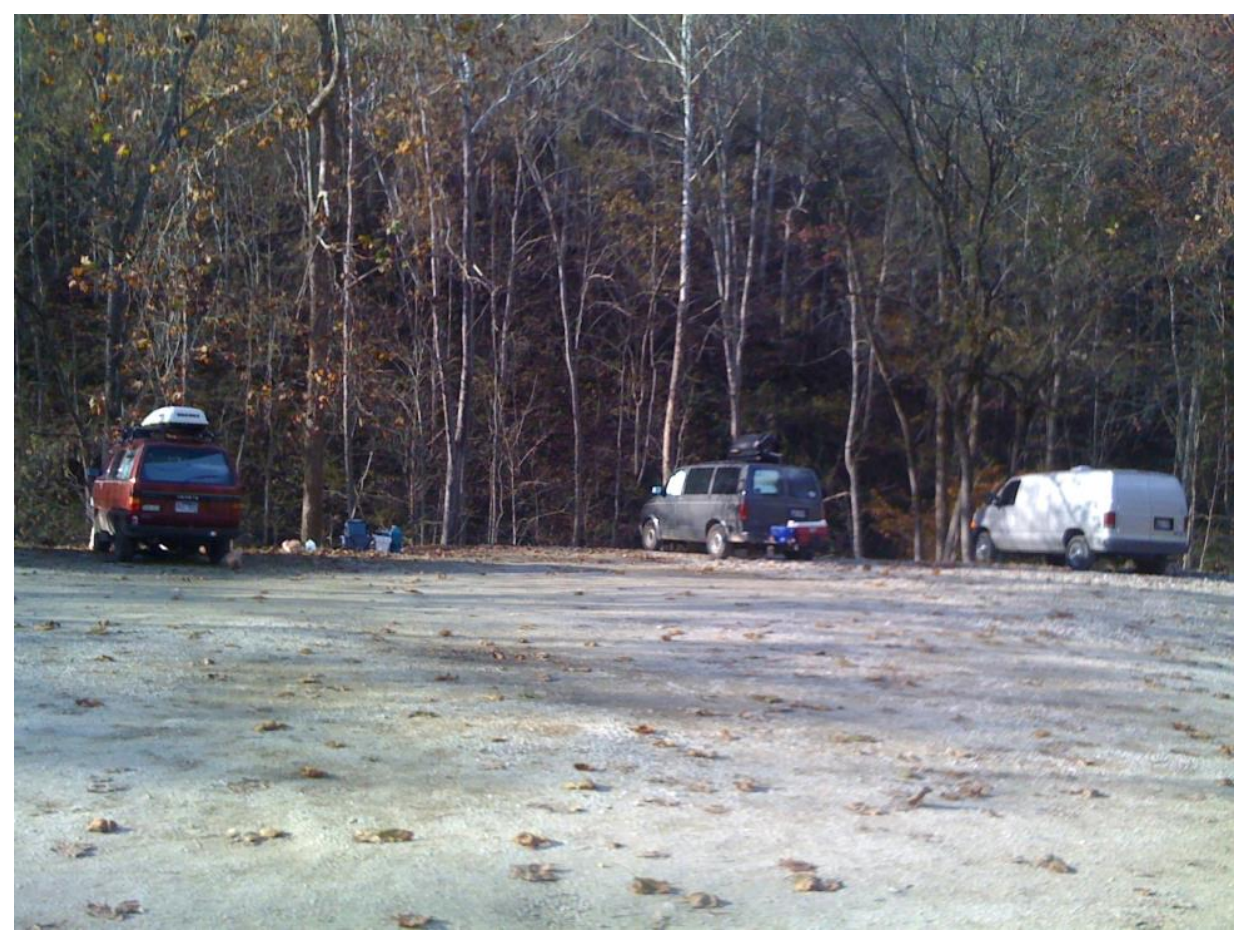

Figure 1 


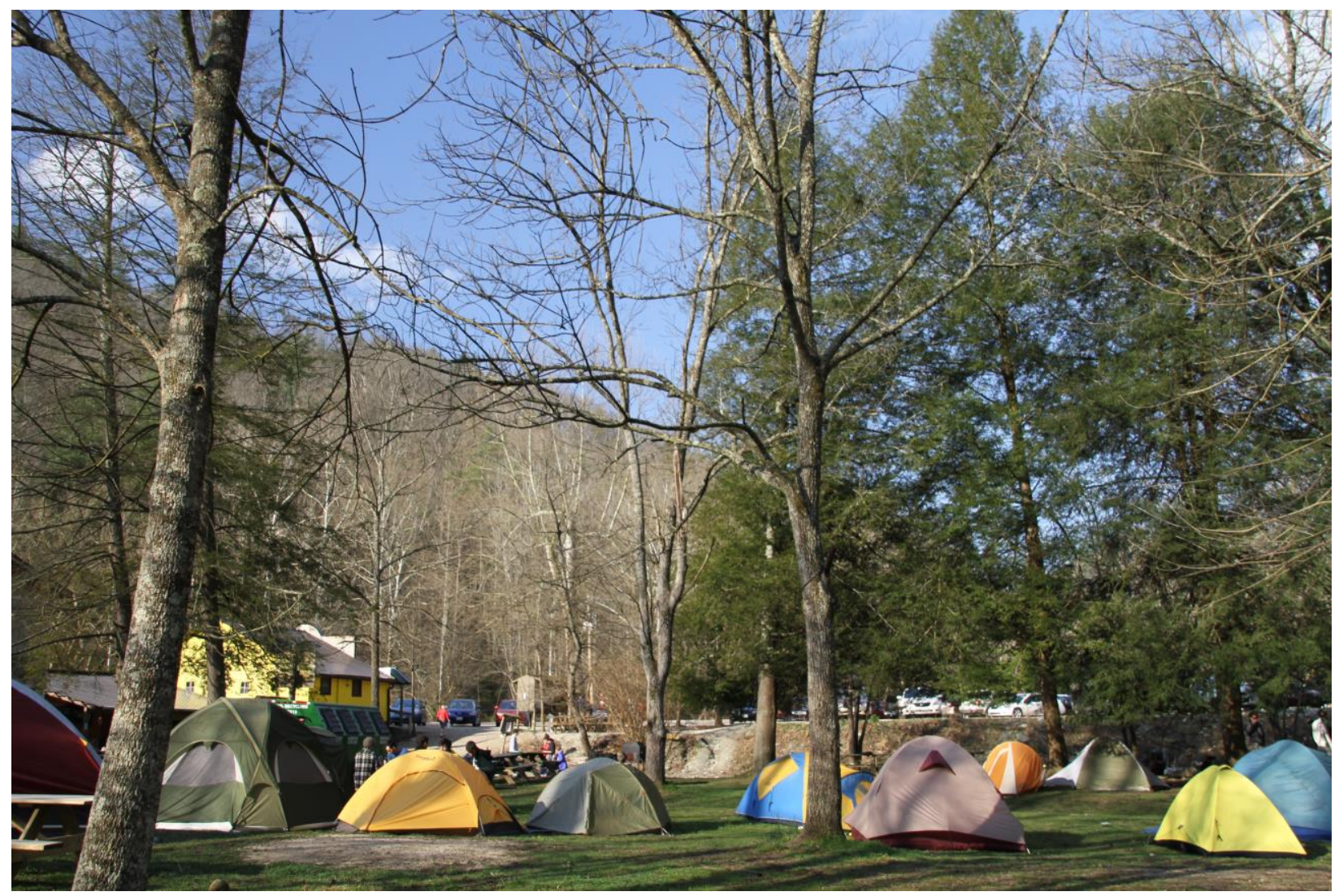

Figure 2 


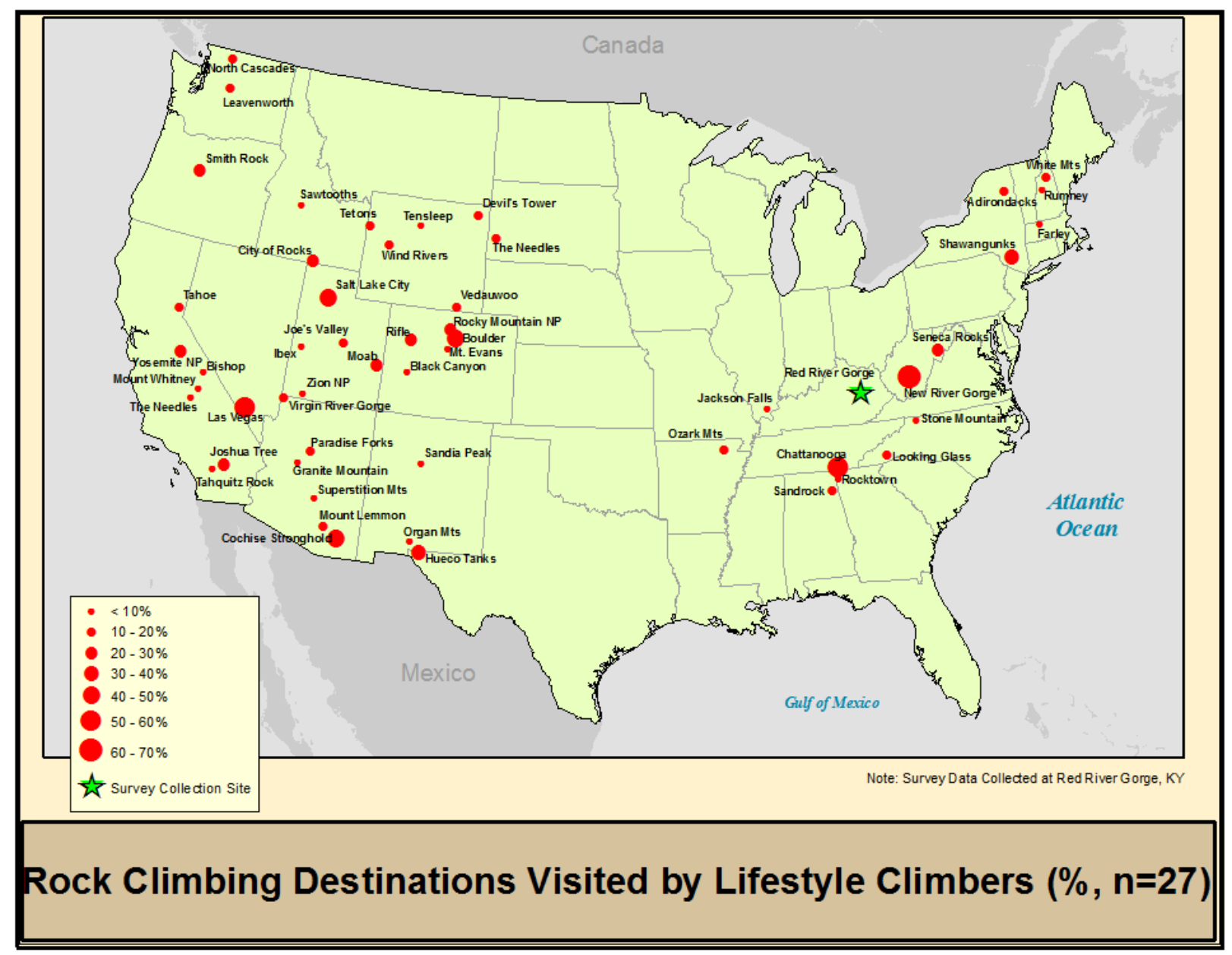

Figure 3 


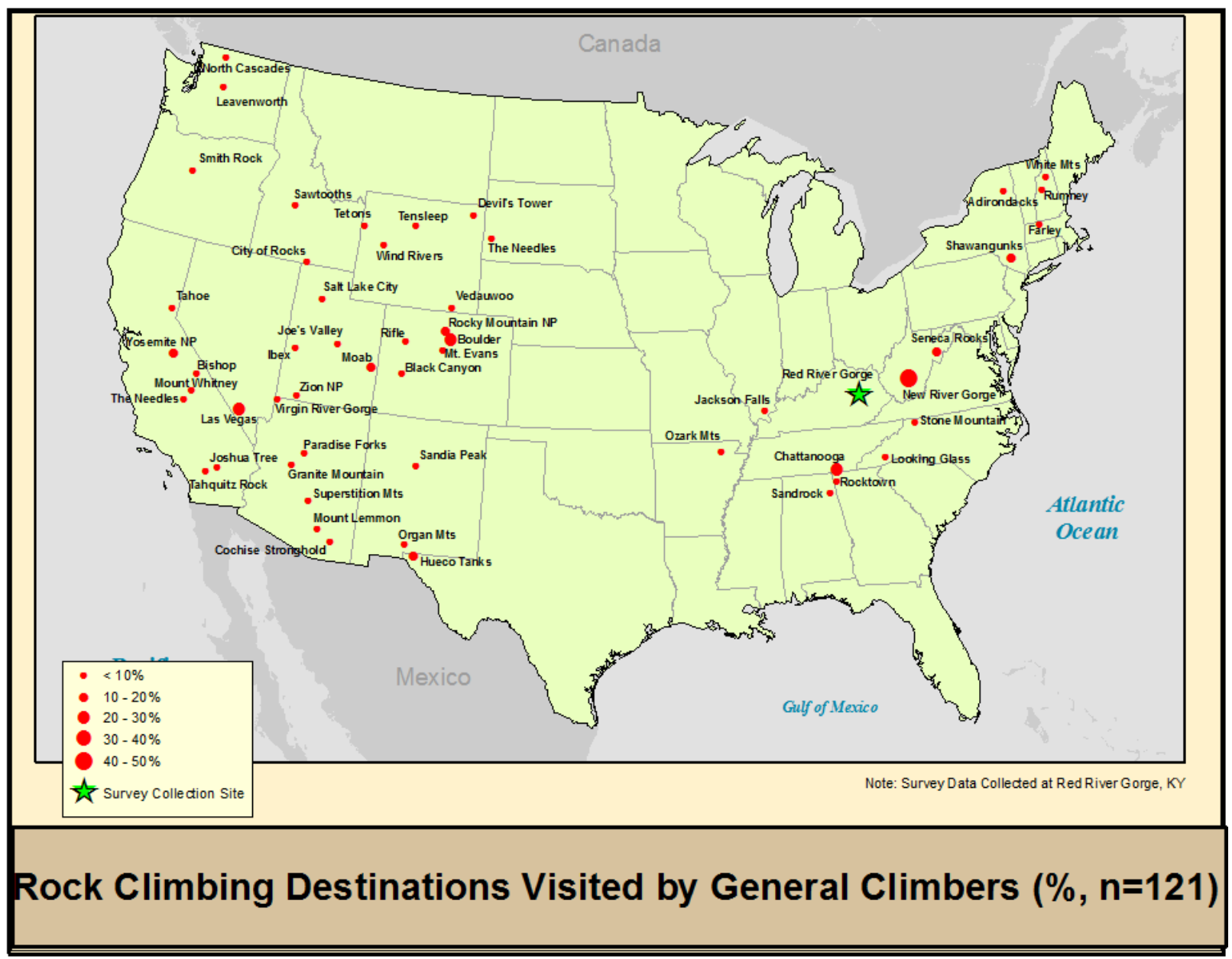

Figure 4 